\title{
Effect of cigarette smoking on the specific antibody response in pigeon fanciers
}

\author{
K ANDERSON, S M MORRISON, S BOURKE, G BOYD \\ From the Department of Respiratory Medicine, Glasgow Royal Infirmary
}

\begin{abstract}
Titres of circulating IgG antibodies to pigeon gammaglobulin and end expired carbon monoxide concentrations were measured in 86 pigeon fanciers attending the "Show of the Year." Antibody levels were significantly higher in non-smokers and in those with end expired carbon monoxide concentrations below 10 parts per million.
\end{abstract}

Cigarette smoking affects various components of the immune response.' Morgan et al noted the suppressive effect of cigarette smoking in patients susceptible to extrinsic allergic alveolitis ${ }^{2}$ and we have reported similar observations, finding circulating IgG specific for pigeon antigen in $55 \%$ of nonsmoking and $4 \%$ of smoking pigeon fanciers. ${ }^{3}$ We are unaware of any previous studies in which an objective indicator of cigarette smoking has been used to investigate subjects susceptible to the effects of antigen inhalation. Cigarette consumption can be assessed by the measurement of end expired carbon monoxide by means of a portable carbon monoxide meter. ${ }^{4}$

\section{Methods}

During a morning at the "Show of the Year" in Blackpool in January 1987 we assessed 86 volunteer pigeon fanciers. A questionnaire (administered by doctors) concerning antigen exposure and cigarette smoking history was completed and blood obtained for measurement of circulating specific IgG by enzyme linked immunosorbent assay (ELISA), with pigeon gammaglobulin as antigen. End expired carbon monoxide concentrations were determined with a portable hand held meter (ECO-Check, PK Morgan Ltd, England). The subject held his or her breath for 20 seconds and exhaled through a one way valve into the meter, which incorporated an alcohol filter. No information about the purpose of the meter was given before a breath sample was obtained. The carbon monoxide concentration in parts per million (ppm) was displayed digitally on the side of the meter, being freely visible to the subject. For the purpose of this study an index of pigeon antigen exposure was made by combining the fanciers' own estimates of the numbers of birds kept and the hours spent in the pigeon loft in one week (pigeon exposure index $=$ pigeon number $\times$ weekly hours $\times 100^{-1}$ ). KruskalWallis one way analysis of variance was used to assess the significance of the findings.

Address for reprint requests: Dr $\mathbf{K}$ Anderson, Department of Respiratory Medicine, Queen Elizabeth Building, Glasgow Royal Infirmary, Glasgow G31 2ES.

Accepted 28 April 1988
Results

The results are shown in figures 1 and 2 . Of the 86 subjects studied, 67 were non-smokers and half of these (33) had IgGconcentrations of over $8 \mu \mathrm{g} / \mathrm{ml}$, a level associated with the

Specific

IgG antibody

$(\mu \mathrm{g} / \mathrm{ml})$

1801 .

$100\rfloor$

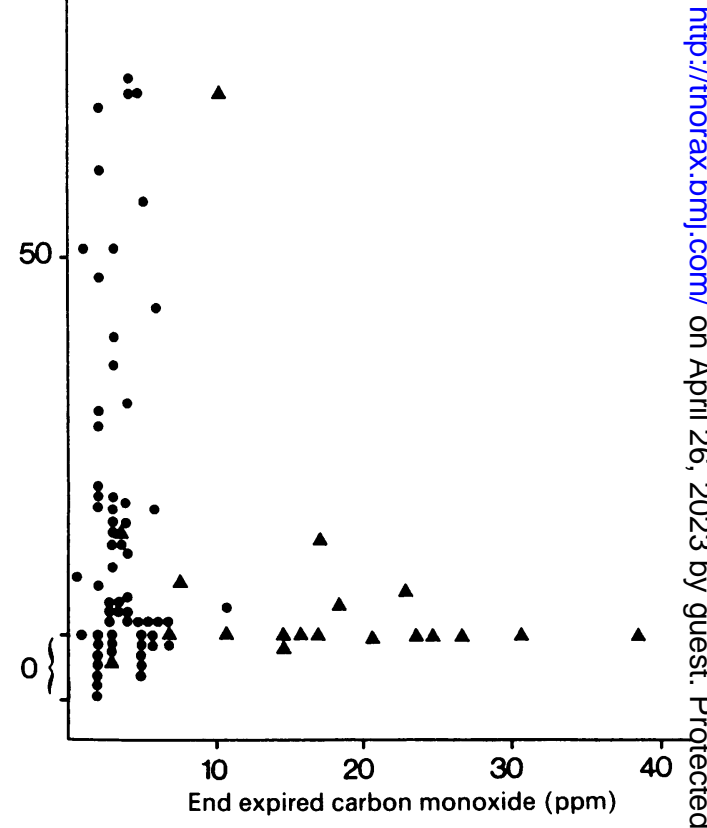

Fig 1 Specific anti-pigeon gammaglobulin (IgG) antibody and end expired carbon monoxide for smokers and nonsmokers (according to smoking history given). 
Specific

IgG antibody

$(\mu \mathrm{g} / \mathrm{ml})$

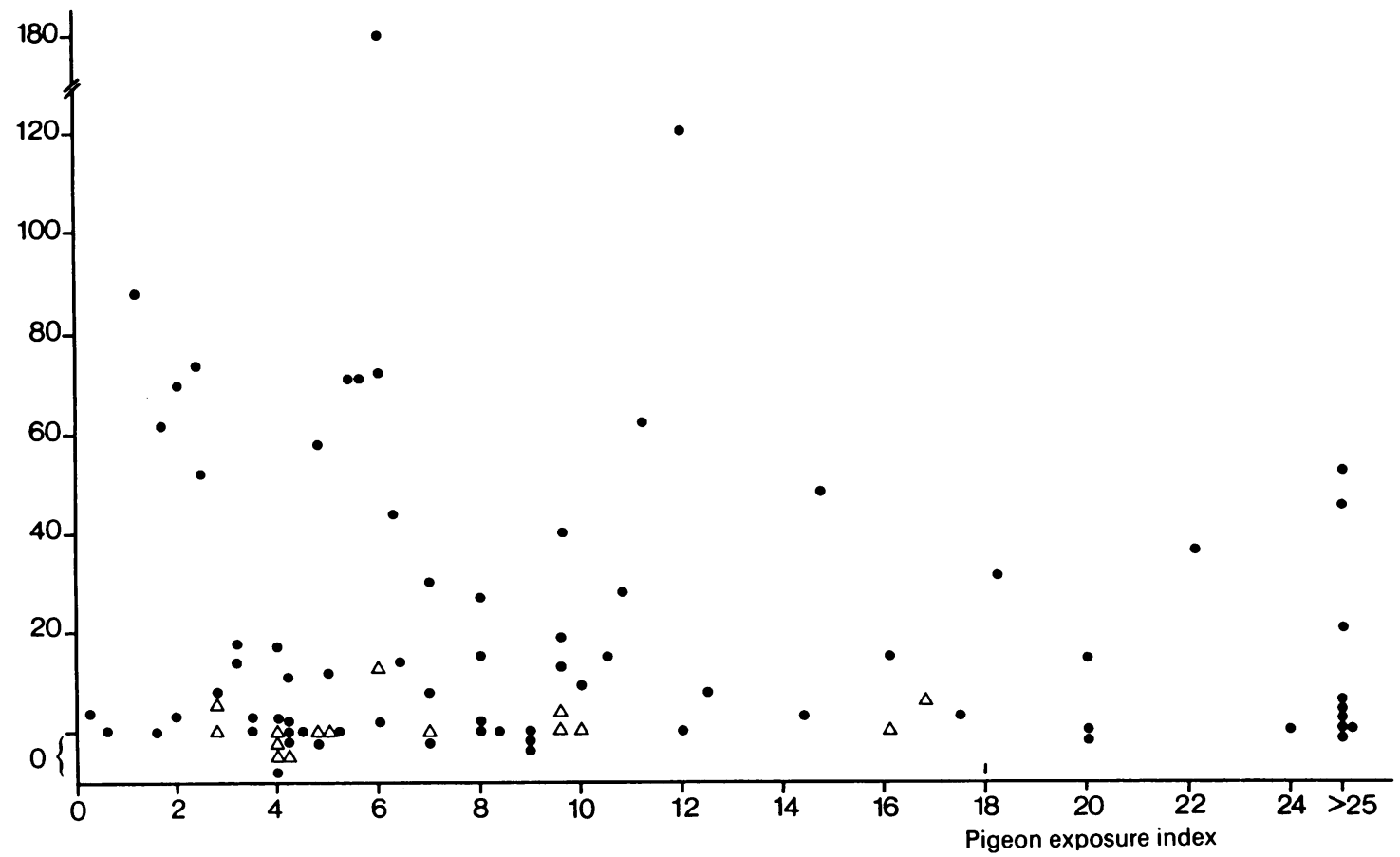

Fig 2 Specific anti-pigeon gammaglobulin ( $\operatorname{Ig} G$ ) antibody and pigeon exposure index for those with end expired carbon monoxide concentrations of under $10 \mathrm{ppm}(\bullet)$ and $10 \mathrm{ppm}$ or more $(\Delta)$.

presence of clinical disease ${ }^{5}$ (fig 1). Only three of the 19 smokers had IgG levels greater than $8 \mu \mathrm{g} / \mathrm{ml}$. Antibody titres were significantly higher in non-smokers than in smokers $(H=7 \cdot 3, p=0.007)$ and in subjects with end tidal carbon monoxide concentrations of less than $10 \mathrm{ppm}$ than in those with concentrations of $10 \mathrm{ppm}$ or more $(\mathrm{H}=8 \cdot 2, \mathrm{p}=0.004)$.

There was no significant difference in pigeon exposure index between subjects with end tidal carbon monoxide concentrations of less than $10 \mathrm{ppm}$ and of $10 \mathrm{ppm}$ or more (pigeon exposure index range 32-52 500 pigeon hours/week; $(\mathrm{H}=1 \cdot 3, \mathrm{p}=0 \cdot 23)(\mathrm{fig} 2)$.

\section{Discussion}

This study confirms the observation that cigarette smoking influences the specific IgG response in pigeon fanciers. Some smokers did have antibody, but they tended to have lower carbon monoxide concentrations, which might reflect differing smoking habits among the subjects (such as inhaling and not inhaling, ${ }^{6}$ and smoking different types of cigarettes') or result from the relatively short half life of carbon monoxide (four hours in resting subjects ${ }^{8}$ ). The data in figure 1 suggest that a concentration of $10 \mathrm{ppm}$ carbon monoxide reasonably divides the smokers from the non-smokers. On this basis four smokers would have been misclassified as non-smokers and one non-smoker as a smoker. Some of the non-smokers whose breath carbon monoxide was in the lower range may have given an incorrect history, but in most cases (66/67) the smoking history given appeared to be accurate. Pigeon fanciers might give a more accurate smoking history than other subjects ${ }^{9}$ because of a wish to attribute symptoms to anything other than pigeons.

The subjects studied were volunteers and they may therefore have been more likely to present if symptoms were present. The finding of circulating antibody in half of the subjects is not unexpected but is likely to reflect the findings in a symptomatic population rather than the prevalence of circulating antibody in the population who attended the pigeon meeting. Previous work suggests that about one third of subjects with higher circulating antibody levels would have symptoms of pigeon breeder's disease. ${ }^{10}$ This study was intended to evaluate a marker of cigarette smoking that might be related to the antibody response, so we have not included an assessment of symptoms.

An estimate of antigen exposure was used to confirm that antigen exposure in non-smokers and smokers was similar. An unexpected finding was the lack of relationship between the antibody response and the estimated degree of antigen exposure. The relationship between antigen exposure and the antibody response is complex. Some workers have reported 
that precipitins occur more commonly as the estimated exposure to pigeons increases," though antibody levels are often highest in subjects who keep small numbers of pigeons," possibly as a result of attempted self regulation in those who are or who have been suffering from symptoms. Pigeon fanciers who develop fulminant disease are more often those who have kept pigeons for less than 10 years. ${ }^{10}$ Pigeon breeder's disease is rarely encountered in those with more prolonged exposure, which suggests an element of higher innate susceptibility in those most severely affected. There may be other factors that we have not considered in our calculation of exposure. We are unaware of work directly comparing measured antigen exposure and antibody response.

Discrepancies between previous studies and ours are probably explained by the limitations of using this estimated value and a single serum sample to represent a more dynamic reaction within the lung. The impaired antibody response in smoking pigeon fanciers seems not to be due to their having different antigen exposure from non-smokers and may be more dependent on the quantity of exposure to cigarette smoke. An end expired carbon monoxide level of $10 \mathrm{ppm}$ or more was rarely associated with a measurable antibody level in this study. The clinical implication for a regular smoker with undiagnosed lung disease is that, while the long term effects of persistent antigen exposure in cigarette smokers remain unknown, the absence of circulating antibody should not imply absence of exposure to antigen.

We suggest that future studies of the effects of cigarette smoking on the immune response should include measurements of a marker of smoke exposure in order to determine whether the effects are dose related.

\section{References}

1 Holt PG. Immune and inflammatory function in cigarette smokers. Thorax 1987;42:241-9.

2 Morgan DC, Smyth JT, Lister RW, Pethybridge RJ. Cheș symptoms and farmers' lung: a community survey. $\mathrm{Br} J$ Ind $\mathrm{Me}$ 1973;30:259-61.

3 McSharry C, Banham SW, Boyd G. Effect of cigarette smoking on. the antibody response to inhaled antigens and the prevalence op extrinsic allergic alveolitis among pigeon breeders. Clin Allergy 1985;15:487-94.

4 Jarvis MJ, Belcher M, Vesey C, Hutchinson DCS. Low cos? carbon monoxide monitors in smoking assessment. Thorax 1986;41:886-7.

5 McSharry C, Banham SW, Lynch PP, Boyd G. Antibod卢 measurement in extrinsic allergic alveolitis. Eur $J$ Respir Dis 1984;65:259-65.

6 Wald NJ, Idle M, Boreham J, Bailey A. Inhaling habits amonge smokers of different types of cigarette. Thorax 1980;35:925-8.

7 Wald NJ, Boreham A. Relative intakes of tar, nicotine and carboł monoxide from cigarettes of different yields. Thorax. 1984;39:361-4.

8 Coburn RF, Forster RE, Kane PB. Considerations of the physiological variables that determine the blood carboxy haemoglobin concentration in man. J Clin Invest 1965;440 1899-10.

9 Ohlin P, Lundh B, Westling H. Carbon monoxide levels an $\overrightarrow{80}$ reported cessation of smoking. Psychopharmacolog 1976;49:263-5.

10 Banham SW, McSharry C, Lynch PP, Boyd G. Relationshipg between avian exposure, humoral immune response, and pigeos breeders disease among Scottish pigeon fanciers. Thora? 1986;41:274-8.

11 Fink JN, Schleuter DP, Sossman AJ, et al. Clinical survey of pigeon breeders. Chest 1972;62:277-81. 